\title{
Conversational Agents - Exploring Generative Mechanisms and Second-hand Effects of Actualized Technology Affordances
}

\author{
Lena Waizenegger \\ Auckland University of \\ Technology \\ Lena.waizenegger@aut.ac.nz
}

\author{
Isabella Seeber \\ University of Innsbruck \\ Isabella.Seeber@uibk.ac.at
}

\author{
Gregory Dawson \\ Arizona State University \\ gregorysdawson@gmail.com
}

\author{
Kevin C. Desouza \\ Queensland University of \\ Technology \\ kevin.c.desouza@gmail.com
}

\begin{abstract}
Many organisations jumped on the bandwagon and implemented conversational agents (CAs) as a new communication channel. Customers benefit from shorter resolution times, ubiquitous availability, and consistent and compliant responses. However, despite the hype around CAs and the various benefits for customers, we know little about the effects of external facing CAs on the human workforce. This is crucial to better manage the possible changes in the work organisation. Adopting a critical realist stance and using the lens of technology affordances we explore a) why users increasingly actualize $C A$ affordances and b) the first and second-hand effects of affordance actualisation on customers and human employees. We conducted semi-structured interviews with 18 experts in the field and introduce the term affordance effects pairs describing the relationships between the first and second-hand effects. We further explain which generative mechanisms lead to an increasing actualization of affordances and the associated effects.
\end{abstract}

\section{Introduction}

"By 2020, customers will manage $85 \%$ of their relationship with the enterprise without interacting with a human" [1]. Today, conversational agents (CAs) which are dialogue systems that simulate human conversations using text or spoken language [2] are a popular means to automate the interactions between customers and the organisation.

Organisations across various industries such as retail, insurance, telecommunication, healthcare, and banking, have capitalized on the vast improvement in CAs over the last few years and have implemented the technology in their customer service operations $[3,4]$. One major reason for this was that Microsoft and Facebook developed frameworks that allowed the integration of chatbots in their messaging platforms [5]. This integration represented a huge opportunity for companies as they can embed their CAs in existing social media platforms that most of their customers were already using.

CAs offer different functionalities than traditional technologies such as natural language understanding, natural language creation, friendliness, emotional cues etc. [6, 7]. Particularly, the human-like features of CAs lead to new use practices and challenges when people interact with these technologies in comparison to traditional technologies. Despite the huge adoption of CAs we know little about why people use the different functionalities of CAs and what potential effects they have.

To improve our understanding, we adopt the lens of technology affordances [8-10]. Technology affordances are potentials for action that might be actualised or not depending on the user's skills and intentions $[10,11]$. This lens is suitable as it reduces the "repeating decomposition problem" [10] that often occurs when analysing technical objects. By analysing the characteristics and goals of a user group we can sharply limit the range of properties examined. Therefore, although the technology might have many structural features or technology properties [10] that could lead to various effects, not all of them are "afforded". Consequently, which affordance effects materialize depends on each individual user and if they perceive and actualise the technology affordances of CAs [12].

While we know that CAs can provide an engaging and interactive customer experience $[13,14]$ and therefore improve customer satisfaction, we know little about the effects on the human workforce. This knowledge is crucial to better prepare human employees for a possible change in their work practices and processes. Lack of transparency could lead to a violation of the psychological contract [15] resulting in decreasing work performance. The goal 
of this paper is to understand a) why different affordances of CAs are actualized and b) the effects not just on the immediate user but also on the employees. Hereby, we respond to a call for future research from Leidner et al. [16] to explore the second hand effects of technology affordances to provide a more holistic picture on the effects after actualisation.

\section{Theoretical background}

\subsection{Conversational agents}

In the literature we see a plethora of different terms such as chatbots, digital assistants, cognitive assistants, digital employees and many more [5, 17], which differ in terms of capabilities, interaction medium (voice, text, symbols) and task range. We use the umbrella term conversational agents (CAs) [6] which are defined as "systems that mimic human conversation using text or spoken language" [2, p.1248]. To narrow the scope of our research we only focus on external facing CAs that mainly interact with customers and are implemented to improve the customer experience.

Although the first chatbot named ELIZA was already developed in 1966 by Joseph Weizenbaum [18] technological advances in voice recognition, natural language processing, and machine learning [2], drove the presence of universal chat platforms with socialbots such as Facebook messenger and Google Alto [19]. CAs are now deployed in various industries ranging from education, finance, insurance and healthcare, especially in the field of mental health [4].

CAs have the potential to fulfil customer expectations of 24/7 access, speed, personalisation, and service quality and can provide an interactive and engaging customer experience [13] due to their ubiquitous availability, scalability, natural language processing capabilities and emotional cues. CAs can be leveraged along the whole customer journey. They can engage the customer as soon as she lands on the website by sending a welcome message, it can suggest products based on specific user needs, respond to the most common customer queries in a structured way and record customer satisfaction with suggestions and complaints [20]. Especially information quality, system quality and service quality of chatbots have a significant positive effect on customer experience, but these effects are negatively moderated by perceived risk [14]. CAs have the potential to allow customer service agents to provide a better customer service experience by reducing their wait time and preserving their insights from past experiences that can be leveraged in future applications [21]. While literature suggests that internal facing CAs that assist employees could lead to higher efficiency, engagement, morale and productivity among employees [22], we know little about the effects of external facing CAs on employees. Despite the debate around "robots replacing humans" there is a lack of empirical evidence on the effects of CAs on the human workforce in academic journals [23]. This study should be a first step in addressing this gap.

\subsection{Theory of technology affordance}

The notion of affordances was coined by Gibson [24] derived from the verb "to afford" meaning to allow, manage or bear something [25]. Ecological psychology research built on this term and claimed that an affordance is not just a property of the object itself but of the relationship between an object and an actor and creates an opportunity for action. Hutchby [26] emphasizes the relational character of affordances and states that "the affordance of an object may be different for one species than for another" (p.448). Affordances can be enabling or constraining [26]. Enabling affordances make a particular action possible for a specific structureactor relationship [27], while constraining affordances prevent or complicate the action [26].

In the IS field, this theoretical lens has also been applied e.g. in the following studies [9, 10, 28] and its definition adapted. Volkoff and Strong [27] define affordances as "the potential for behaviours associated with achieving an immediate concrete outcome and arising from the relationship between an object (e.g., an IT artifact) and a goal-oriented actor or actors." (p.823)

Affordances are the possibilities of the actor to use these IT features or a combinations of those depending on their goals, abilities, and lines of actions [29]. Which of these features are actualised is in the disposition of the actors themselves. In order to explore the effects of CA affordances we build on Bernhard et al. [12]'s framework which distinguishes between affordances existence, perception, actualisation and effect. While affordance existence depends on the object's properties with causal potential and the users' goal and expertise, the user first needs to perceive the affordance before being able to actualize it. The actualization of the affordance is the process of executing the affordance that leads to intended effects of the user and the designer of the artefact as well as unintended effects [10]. The affordance effect is an empirical result [30] 
of the actualisation and can lead to immediate outcomes in the short run and ultimate organisational goals in the long run [31]. Leidner et al. [16] showed that the actualization of affordances from the users in their case new hires had effects on them but also on the middle management and non-users. They coined these effects first- and second-hand effects. Hence, while first-hand effects are those directly experienced by the user who actualizes the technology affordance, second-hand effects are those perceived by other stakeholders that were not directly involved in the actualization.

Exploring Slack chatbots, Stoeckli et al. [32] found functional affordances related to receiving information and outcomes of automated workflows, functional affordances related to getting and setting triggers and reminders, functional affordances related to queries and invocations within Slack channels and functional affordances related to the enrichment of messages We want to build on this study of CA affordances and respond to Leidner et al. [16] call to explore the effects of the actualisation of $\mathrm{CA}$ affordances on the customers and human employees.

Besides the effect of the actualized affordances we want to explore why people leverage them with the help of generative mechanisms. Generative mechanisms are causal structures that generate observable events [33]. In our case the observed events are the actualisations of affordances and we look at action-formation mechanisms that explain "how a specific combination of individuals desires, beliefs and action opportunities generate a specific action" [34, p. 23]. Generative mechanisms are therefore a suitable means to explain why customers actualize the different $\mathrm{CA}$ affordances in order to achieve positive effects.

\section{Methodology}

To accomplish our research objectives, we applied a qualitative research approach building on the philosophical underpinnings of critical realism [35]. Critical realism focuses on the real problem and the underlying causes or mechanisms and does not aim to uncover and develop general laws [36]. As we want to explore the generative mechanisms why different technology affordances are actualized and which effects they evoke, we deem critical realism as suitable.

Between March and November 2018, we conducted semi-structured interviews [37] with 18 developers of CAs, managers of organizations that sell CAs as a service, and organizations that have implemented CAs, and experts in the field of AI and CAs in New Zealand (13), USA (4), and Australia
(1). We achieved demographic diversity by interviewing ten men and eight women in an age range from $25-55$ years old from different cultural backgrounds. Selected interviewees had comprehensive knowledge of the overall vision of the CA projects. Most of them were involved in the development, managing or overseeing of the implementation at their company or in customer companies. Moreover, affected employees reported to them when bugs, issues, or other noteworthy events occurred. Hence, the selected interviewees could provide a comprehensive bigger picture of the CAs in use and hence are suitable to answer the interview questions. We followed the dramaturgical model of qualitative interviews by Myers and Newman [38] and a semi-structured approach [37]. We asked questions about the reasons why companies implement CAs, the benefits and challenges of CAs, which tasks the CAs perform, the effects on the human employees' work processes and practices, how customers use the CAs and the emotional reaction of human employees and customers towards CAs. However, we remained open to any new perspectives from the participants.

The interviews took between 30 to 90 minutes and were conducted either face to face or via Skype. All interviews were conducted by the first and second author. The interview guideline was developed by the research team and went through two iterative circles. The interviews were audio-recorded and transcribed, and the data analysis occurred in two major phases. In line with many other IS studies that follow a critical realist stance, we applied the abductive logic $[39,40]$. The goal of abductive theorizing is to find the best explanation. It usually starts with an incomplete set of observations and ends with the delineation of an explanatory hypothesis which fits an organized set of patterns [41].

In the first phase, two of the authors conducted a thematic analysis [42] using NVIVO 12 as software tool that supported the process. After familiarizing ourselves with the data by reading the transcripts or listening to the audio files again, we started the coding process using initial codes [42]. These codes emerged from the data and were reviewed. In the next round, we developed and validated themes by iterating through codes and themes in discussions with the entire research team. In the second phase, we identified the theory of technology affordances [28] as the most suitable lens to explain the patterns we have found in the data. We then went back and forth between theory and data following the abductive logic and tried to find the best explanation of a) the generative mechanisms that lead people to actualize 
the affordances and b) the effects of the affordances on customers and human employees.

\section{Findings and Discussion}

Based on our data analysis, we identified three first order affordances that allow the actualisation of second-order affordances and their first and secondhand effects on customers and employees (see Table 1). Next, we explain for each affordance the typical user intentions and characteristics and their generative mechanisms. To protect anonymity, all company and CA names were pseudonymized.

\subsection{Self-servicing}

Self-servicing describes an affordance that users actualize to get their questions answered or tasks fulfilled, which they couldn't do without a counterpart. Respondents who were time conscious, impatient, and were busy during normal working hours perceived and actualized the affordance of selfservicing. We have identified two underlying generative mechanisms that drive self-servicing through a CA to achieve the first order effects. First, people nowadays experience ubiquitous connectivity meaning that they can be constantly connected to the Internet independent of time and location [43]. Therefore, they can talk to a CA if they have any questions or a problem that needs to be solved anytime and everywhere. Second, people expect instant gratification [44]. Due to the access of information and knowledge everywhere and anytime, people expect to get their questions answered immediately and not wait for a suitable customer service employee to get back to them. This need for instant gratification is emphasized by Brad the product owner of the chatbot Sophie that was implemented in the Insurance company WHYB who replied the following when asked who uses Sophie, "Everyone. Fundamentally, customers of any age just want their question answered quickly. So if this does it for them in a way that's better than other options, they will go for it irrespective of whether they are 1 or 80. They just want the answer."

Actualizing this first level affordance allows the person to realize second-order affordances, which our respondents viewed as the instantaneous solving of fact-based questions and executing tasks.

Most CAs are programmed to solve fact-based questions like "what is an excess" or "do you cover knees or shoulders" in an insurance context where they pull the information from an integrated database. Customers often do not want to go through the extensive list of FAQs and generally prefer asking the CA to get the answer instantaneously. More sophisticated CAs can provide answers based on the analysis of the provided facts of the users. A logistics firm, Logistics Pro, implemented a chatbot that has the following functionality: "we are in the executing/performance task. Can you track my package, where is the next pickup location, can I make a delivery change, how much is it to send it from zip code A to B? The CA can identify the closest Logistics Pro location depending on the user's position. Further, it can calculate the costs of how much it is to send a package from one specific location to another. In these cases, the CA executes tasks and needs to have analytical capabilities that the user can actualize. As CAs develop advanced capabilities and are integrated with other automation technologies such as Robotic Process Automation (RPA), they can execute more complex tasks more effectively and efficiently. Lisa an IT consultant explains that they could reduce the resolution time of the insurance claim process from 48 to 4 hours which led to an improvement in customer experience and freeing up human resources, who could then focus on relationship building and personalized customer care.

The actualization of the affordances results in shorter resolution times, improved customer service, higher convenience, and cost and efforts savings which ultimately leads to higher customer satisfaction. Brad explains "We track customer satisfaction through using NPS data so whenever a customer has an interaction with us we survey them to understand what worked and what didn't. we have seen that customer who self-service digitally have a higher satisfaction than those who come through our call centre for example." CAs still fail and may not understand what is being asked of them and may even provide incorrect resolutions leading to customer frustrations. Managing customer expectations is critical. Users often expect CAs to be much more skilled with a broader knowledge base than they actually have. After examining the interaction logs, Nathan the product owner of a chatbot in a large engineering and advisory company says that customers drop out after the third question due to frustration: " [customers] get really frustrated - so we get a surprising number of people who'll drop out after the third question that seems to be the kicker. You know, we can't even hold their attention for 45 seconds". Actualizing the first and second order affordances does not just lead to positive and negative effects for the customers but also for employees.

The increase in self-servicing customers leads to a reduction of the often mundane and repetitive tasks 
for the customer service employees, as these can be taken over by the CA. Employees can now focus on the complex cases that are more interesting to solve and that require a broader knowledge field as well as contextualized information and empathy. This shift from highly repetitive to more demanding and interesting cases could lead to higher employee satisfaction and a higher employee retention rate which is crucial as employee turnover is a big problem in the customer service industry. On the other hand, as CAs become more sophisticated they will encroach on tasks that were reserved for humans. Therefore, the increased actualization of the selfservicing affordance of CAs also leads to a threat of job loss for customer service employees. Implementing CAs can lead to work redesign, restructuring and even downsizing of the workforce. This is emphasized by Lucy the HR manager of one of the global leaders of computer hardware and software. "so when we went to our new HR model which was April 2017, there was a reduction in headcount [...], but there was also a complete restructure of what we did, how we did it. Part of that was enabled because we had a CA-enabled first line advice for our managers and our people so that they could go to a bot before they could track us down." CAs do not just impact the existing workforce but also future hires. The product manager of a company that creates digital employees explains: "but you're also eliminating job openings, you know, like let's say a company wasn't looking to replace their contact centre staff but they bring in digital employees to fill in a role that would normally be fulfilled by a person. So therefore the people they were going to hire are no longer going to be hired.",

\subsection{Simulating a human-like interaction}

This affordance allows people to engage in a caring, (non)task-oriented communication. Customers enjoy interacting with CAs due to their anthropomorphic attributes such as natural language understanding, personality and empathetic cues. Customers actualize the technology affordance simulating a human-like interaction and engage so much in the conversation that they even start arguing with the CA about spelling and grammar as Jacob noted. "And someone was trying to make a booking and was trying to fly to Illinois but then got in an argument with Tony because they didn't believe Illinois should have two ll."

Customers that actualize the technology affordance of simulating a human-like experience are usually technology enthusiasts and curious to try it out as a new communication channel. We identified three generative mechanisms that can explain why this affordance results in such outcomes. First, we observed a sharp rise in mental health issues over the last decade [45]. However, the required medical resources are often not available or too costly [46]. On the other hand, 5.1 billion people have smartphones [47] and 4.4 billion people are active internet users (58\% global pop.) which allows to leverage medical online advice especially through CAs. Second, more and more people suffer from loneliness in our hyper-connected world [48] and therefore search for friendship, devotion and love on the internet. Missing friendship and affection in the physical world drives a lot of people online [49] and a CA with human-like attributes could be a perfect substitute for the lack of human interaction offline. Third, many people nowadays experience so called micro-boredom [43] and escape in the virtual world. Alternatively, they can chit-chat with a CA and spend their time talking to a computer system. People are embarrassed to talk about their personal issues with customer service employees and therefore, disclose much more information about themselves when they can keep their anonymity [50]. The CA is therefore a preferable mean to get answers on embarrassing topics without disclosing their real identity.

Through the actualization of simulating a humanlike interaction second-order affordances can be actualized such as help-seeking for personal issues, socializing, mitigating boredom and leveraging anonymity. One of the most promising use cases of CAs is in the healthcare sector to fight mental illnesses such as depression or obsessive compulsory behaviour. The chief clinical officer Loreen of a notfor-profit organization that offers mental support through the CA "Angel" noted that an increasing number of people are struggling with mental diseases and there are not enough resources to help all of them. She elaborates "there are many barriers that people experience all over the world in getting to one of these skilled clinicians. There is cost barriers, racial barriers, they cannot take the time from work, transportation barriers, etc." Clients can access CAs $24 / 7$ and especially at night, when access to human resources is limited as outlined by Loreen "we find that many people log into Angel in the middle of the night when their symptoms are striking them. And they get real time help in the moment with their symptoms. And you don't need to wait until traditional business hours to speak to someone or to remember to tell what they were experiencing. They can do that right there in the moment." (Loreen) Clients chat to a CA when they are bored. Jacob shared an interaction log he came across. "I' $m$ bored what are you doing? And Tony (the chatbot) is like 
oh can I help and they are like nah I'm just having a chat." Clients feel more comfortable discussing sensitive topics with CAs for the perception that they will not be judged and the interaction is anonymous. Therefore, it is often a balance for CA designers to make the CA human-like enough that people have an enjoyable natural conversation, whilst at the same time making it identifiable as a machine as people enjoy the anonymity associated with it.

Brad explains "But not with a chatbot, people are really open because it's kind of anonymous. It's a computer so people are really open about "I've got this thing, is it covered" which you might not ask a salesperson on the phone because its person who might judge you. There is an interesting balance between humanising a chatbot and making sure it is very clearly a robot so people do feel comfortable opening up and they will engage."

Through the actualization of the first and second order affordances customers experience many benefits such as a personalized interaction and advice, a counterpart to talk to mitigate loneliness and boredom, receiving advice on embarrassing topics that they do not dare to discuss with a human agent and first and foremost an enjoyable interaction with accurate and consistent responses. Due to the perceived anonymity when talking to a CA, clients can get questions answered that they would feel embarrassed to ask a human agent and therefore get better advice that fits their exact circumstances.

The skill of building empathetic relationships used to be solely reserved to human employees. The capability of expressing social and emotional cues allows CAs to also build engaging interactions. However, there are still instances where human interactions are preferred. As Jacob notes "When things go wrong you don't really want to talk to a machine, it doesn't matter how friendly the machine is you really want to talk to someone with empathy and as much as we can code it in there, you want to talk to someone with real empathy instead of puppet empathy. And this is what people are looking into right now, blending in real emotions."

For example, actualizing the second order affordance "help seeking for personal issues" like in the case of mental health problems led to personalized advice for customers, but could also result in job loss for human employees in the long run. Tasks that require empathy and contextual information were previously reserved for humans but are now starting to be taken over by CAs. On the other hand, many CAs are still very rudimentary and therefore, can only answer a narrow range of questions, which might lead to frustration on the customer side. Humans are still much better in contextualized tasks that require knowledge across different areas and therefore, human employees benefit from the drawback of CAs and safeguard their employability.

\subsection{Personal assistance}

This affordance describes the CA offerings that people could perform themselves but choose to outsource to the CA. People that use CAs as personal assistant are usually technology-affine and early adopters of technology, they are very efficiency driven and cost sensitive and want to optimize the allocation of tasks to save time for the more critical to-dos. For this affordance, we found two underlying generative mechanisms.

People have less and less time despite the technology support that facilitates many work practices and processes. Many people fall into the trap of escalating engagement where expectations towards availability and responsiveness keep rising [51]. Due to this time-poorness, they outsource some of their tasks and use their CAs as a true personal assistant. Second, people seek ways to increase their own efficiency and effectiveness and do not waste their time on administrative tasks. By interacting with the CA they co-create value and improve their communication, achieve better task management, enhanced information retrieval, enhanced learning and better data-driven decisions [52]. For example, Sean the director of an AI association uses a diary management $\mathrm{CA}$ which engages in an email conversation with his contacts to find a suitable day and time for him and his colleague to meet. He can go back in the email exchange and follow the conversation that the bot has with his colleague as it is all in human-readable language. After the CA finds a suitable time Sean explains that " $a$ diary appointment will turn up in the diary with all of the information I need to turn up for coffee with someone, or to meet someone on Hangouts or Skype". Several of our interviewees stated that digital personal assistants will be commonplace in the future. Rodger, the CEO of a company that develops conversational platforms states: "At the moment you've got bots that talk to humans and look stuff up and I think in the next iteration is bots that talk to bots, so I won't have to talk to 100 different bots with all the different companies. I will only talk to mine, you know? My bot's going to be called Fredrick or something like that. I'll say hey Fredrick the Great, do this for me. Now Fredrick knows all of my details and what I want, doesn't release anything personal or private, and deals with all of the other instances that 
Table 1 Overview of technology affordances and effects

\begin{tabular}{|c|c|c|c|c|c|}
\hline $\begin{array}{l}\text { First order } \\
\text { affordance }\end{array}$ & $\begin{array}{l}\text { User characteristics } \\
\text { and intentions }\end{array}$ & $\begin{array}{l}\text { Generative } \\
\text { mechanism }\end{array}$ & $\begin{array}{l}\text { Second order } \\
\text { affordances }\end{array}$ & First-hand effects for customers & Second-hand effects for employees \\
\hline $\begin{array}{l}\text { Self-servicing } \\
\text { "CA offerings that } \\
\text { users actualize to } \\
\text { get their questions } \\
\text { answered or tasks } \\
\text { fulfilled, which } \\
\text { they couldn't do } \\
\text { without a } \\
\text { counterpart" }\end{array}$ & $\begin{array}{l}\text { - need for immediacy } \\
\text { and pragmatism } \\
\text { - } \text { efficiency driven } \\
\text { - technology affine }\end{array}$ & $\begin{array}{ll}\text { - } & \text { ubiquitous } \\
\text { connectivity } \\
\text { - } & \text { instant gratification }\end{array}$ & $\begin{array}{l}\text { - instantaneous } \\
\text { solving of fact- } \\
\text { based questions } \\
\text { - executing tasks }\end{array}$ & $\begin{array}{ll}+ & \text { shorter resolution time } \\
+ & \text { improved customer service } \\
+ & \text { higher convenience } \\
+ & \text { cost and time savings } \\
+ & \text { instant support } \\
+ & \text { accurate, compliant and consistent } \\
& \text { responses } \\
+ & \text { improved efficiency } \\
+ & \text { improved customer satisfaction } \\
+ & \text { reduction of geographical barriers } \\
- & \text { customer frustration } \\
- & \text { wrong answers given }\end{array}$ & $\begin{array}{ll}+ & \text { reduction of mundane and } \\
& \text { repetitive tasks } \\
+ & \text { reduction of workload } \\
+ & \text { focus on more complex cases } \\
+ & \text { focus on relationship building } \\
& \text { with customer } \\
+ & \text { higher employee satisfaction } \\
+ & \text { higher retention rate } \\
- & \text { threat of job loss } \\
- & \text { need to upskill } \\
- & \text { decrease in new hires } \\
- & \text { requires intensive CA training } \\
- & \text { role ambiguity }\end{array}$ \\
\hline $\begin{array}{l}\text { Simulating a } \\
\text { human-like } \\
\text { interaction } \\
\text { "CA offerings that } \\
\text { engage people in a } \\
\text { caring, (non)task- } \\
\text { oriented } \\
\text { communication", }\end{array}$ & 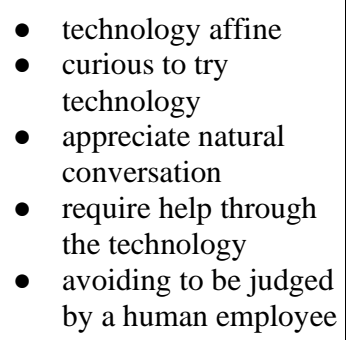 & $\begin{array}{ll}\text { - } & \text { mental health } \\
\text { - } & \text { issues } \\
\text { - } & \text { loneliness } \\
\text { micro-boredom }\end{array}$ & $\begin{array}{ll}\text { - } & \text { Help-seeking for } \\
& \text { personal issues } \\
\text { - } & \text { Socializing } \\
\text { - } & \text { mitigating boredom } \\
\text { - } & \text { leveraging } \\
& \text { anonymity }\end{array}$ & 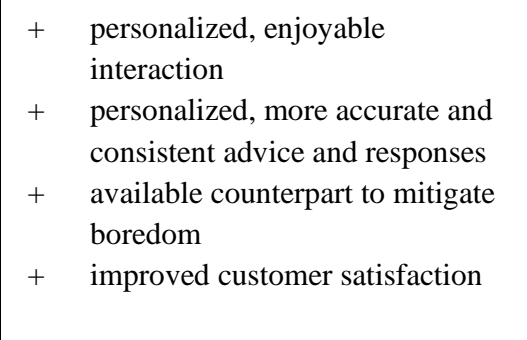 & 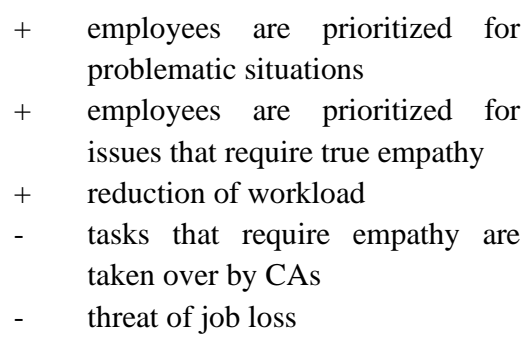 \\
\hline $\begin{array}{l}\text { personal assistance } \\
\text { "CA offerings that } \\
\text { people could } \\
\text { perform themselves } \\
\text { but choose to } \\
\text { outsource to the } \\
\text { CA" }\end{array}$ & $\begin{array}{l}\text { - } \text { technology-affine } \\
\text { - } \text { early adopters of } \\
\text { technology } \\
\text { - efficiency driven } \\
\text { - } \text { cost sensitive } \\
\text { desire to optimize the } \\
\text { allocation of tasks } \\
\text { - desire to save time for } \\
\text { the more critical to- } \\
\text { dos }\end{array}$ & 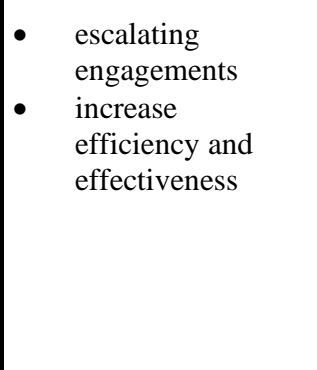 & $\begin{array}{l}\text { - relief from } \\
\text { mundane tasks }\end{array}$ & $\begin{array}{ll}+ & \text { time savings } \\
+ & \text { cost reduction } \\
+ & \text { improved efficiency } \\
+ & \text { increased convenience } \\
+ & \text { more accurate information } \\
- & \text { data privacy issues } \\
- & \text { data security issues }\end{array}$ & $\begin{array}{ll}- & \text { threat of job loss } \\
- & \text { decrease in new hires }\end{array}$ \\
\hline
\end{tabular}


I need; doesn't need API integrations because it uses conversational interactions. "

Personal digital assistants provide benefits such as cost and time savings, increased convenience, and personalized, and accurate information provision. Sean notes "It saves me probably one to two hours a week." On the other hand, customers might face privacy issue where bots get compromised and personal data is leaking. Leveraging the personal assistant skills of a CA has a direct impact on human employees as the CA takes over the tasks of a personal assistant at a much lower cost, which particularly affects people with lower education levels as outlined by the head researcher of a global IT firm: "But I have a general concern around technology that a lot of the jobs that don't require a lot of education will get automated. How do we deal with that on a societal level."

In our further analysis, we found that affordance effects can occur in pairs (affordance effect pairs) and that sometimes actualization of affordances did not meet the expected outcome (affordance actualization failure).

We saw that the actualization of the affordances results in +/- first-hand effects for customers that are associated with +/- second-hand effects for employees, which we label affordance effect pairs. In some cases the actualization of the technology affordance led to disharmonizing first and second hand effects. These could be positive effects for the customers, but negative effects for the human employee or negative for the customer but positive for the human employee. For example, the actualisation of "personal assistance" leads to time savings for the customer but threatens the jobs of human personal assistants as the CA takes over tasks that fall under their responsibility such as scheduling meetings or note-taking. In other instances, the actualization of technology affordances led to harmonizing first and second-hand effects. This means that the actualization could lead to positive effects for the user and other stakeholders. For instance, the second-order affordance "executing tasks" led to cost and time savings for the customer and a reduction of mundane and repetitive tasks for human employees.

Affordances can be constraining and enabling [26] and therefore preventing or allowing an action to be undertaken. However, in our case, supposedly enabling affordances led to negative effects for the customers due to the rudimentary capabilities of the technology. We call this scenario an affordance actualization failure referring to scenarios where expected enabling affordances could not or only partly be actualized and led to negative first-hand effects for the user. This explains why users can experience negative first-hand effects. Users would most likely not actualize an affordance when they would be aware of the following negative effects. For instance, when a customer actualized the affordance "instantaneous solving of fact-based questions", but the CA did not understand his intent, it would led to frustration and waste of time for the customer.

\section{Contributions, limitations, and future research}

We contribute to the existing theory of technology affordances $[8,10,28]$ in three ways. First, we contribute to the discourse around the relationship between affordance and outcomes [16, 39]. Responding to the call by Leidner et al. [16] to further explore second-hand effects of technology affordances, we found that the actualisation led to various first- and second-hand effects for customers as well as employees. Second, we introduce the term affordance effects pairs and showed that first-and second-hand effects can be harmonizing as well as disharmonizing. Third, we coin the term affordance actualisation failure, where people actualize an affordance, which however leads to negative firsthand effects due to flaws in the IT artefact.

We also contribute to the CA literature $[21,22,32]$ in two ways. First, this paper introduces three CA specific technology affordances [30], which are selfservicing, simulating a human-like interaction, and personal assistance. They enable customers to actualize second order affordances [16] such as executing tasks and socializing and trigger first- and second-hand effects. Second, we explain why CA affordances are actualized leading to first and secondhand effects through generative mechanisms [39].

The findings of this research could be particularly valuable for organisations that are currently implementing or plan to implement CAs. First, knowing about why customers actualise the different affordances in order to satisfy their needs could help managers to decide in which knowledge fields the CA should be trained in. Second, the identified firstand second-hand effects allow managers to develop a more people-oriented performance framework for measuring the success of their CA implementation projects. Consequently, organisations can gain insights not only into the number of accurate and compliant responses given by the CA, but also into the number of more complex customer service cases resolved by human employees and their satisfaction.

The study has limitations. First, whilst our interviewees were directly involved in the development and implementation of CAs, they could 
only describe the effects on the employees from their perspective. Hence, particularly the identified second-hand effects, which address effects on human employees, need additional investigation. Second, the findings are valid for external facing CAs, but are not generalizable to internal facing CAs or CAs used at home such as Alexa and Google Home.

The study also offers several avenues for future research. Future research should further investigate the suggested concepts of affordance effect pairs and affordance actualization failures. Such research could provide in-depth knowledge on how CAs affect employees and customers. Researchers could also adopt the different affordances to unpack why and how different user types perceive and actualize the affordances.

\section{Acknowledgements}

This research was funded by an Auckland University of Technology (AUT) Faculty of Business, Economics and Law Contestable Research Grant and the Austrian Science Fund (FWF): P 29765.

\section{References}

[1]Gartner, "CRM Strategies and Technologies to Understand, Grow and Manage Customer Experiences " 2011, Available: https://www.gartner.com/imagesrv/summits/docs/na/cu stomer-360/C360_2011_brochure_FINAL.pdf.

[2] L. Laranjo et al., "Conversational agents in healthcare: a systematic review," Journal of the American Medical Informatics Association, vol. 25, no. 9, pp. 1248-1258, 2018.

[3] C. Chakrabarti and G. F. Luger, "Artificial conversations for customer service chatter bots: Architecture, algorithms, and evaluation metrics," Expert Systems with Applications, vol. 42, no. 20, pp. 6878-6897, 2015.

[4] T. W. Bickmore, K. Puskar, E. A. Schlenk, L. M. Pfeifer, and S. M. Sereika, "Maintaining reality: Relational agents for antipsychotic medication adherence," Interacting with Computers, vol. 22, no. 4, pp. 276-288, 2010.

[5] M. Skjuve, I. M. Haugstveit, A. Følstad, and P. B. Brandtzaeg, "Help! Is my Chatbot Falling into the Uncanny Valley?: An Empirical Study of User Experience in Human-Chatbot Interaction," Human Technology, vol. 15, no. 1, 2019.

[6] U. Gnewuch, S. Morana, and A. Maedche, "Towards designing cooperative and social conversational agents for customer service," in Thirty Eighth International Conference on Information Systems, Seoul, South Korea, 2017: AISeL.

[7] T. Araujo, "Living up to the chatbot hype: The influence of anthropomorphic design cues and communicative agency framing on conversational agent and company perceptions," Computers in Human Behavior, vol. 85, pp. 183-189, 2018.

[8] P. M. Leonardi, "When flexible routines meet flexible technologies: Affordance, constraint, and the imbrication of human and material agencies," MIS quarterly, vol. 35, no. 1, pp. 147-167, 2011.

[9] P. M. Leonardi, "When does technology use enable network change in organizations? A comparative study of feature use and shared affordances," Mis Quarterly, pp. 749-775, 2013.

[10] M. L. Markus and M. S. Silver, "A foundation for the study of IT effects: A new look at DeSanctis and Poole's concepts of structural features and spirit," Journal of the Association for Information systems, vol. 9, no. 10, pp. 609-632, 2008.

[11] S. Seidel, J. Recker, and J. Vom Brocke, "Sensemaking and sustainable practicing: functional affordances of information systems in green transformations," Mis Quarterly, vol. 37, no. 4, pp. 1275-1299, 2013.

[12] E. Bernhard, J. C. Recker, and A. Burton-Jones, "Understanding the actualization of affordances: A study in the process modeling context," in Thirty Fourth International Conference on Information Systems, Milan, Italy, 2013: AISeL.

[13] M. Chung, E. Ko, H. Joung, and S. J. Kim, "Chatbot eservice and customer satisfaction regarding luxury brands," Journal of Business Research, pp. 1-9, 2018.

[14] J. Trivedi, "Examining the Customer Experience of Using Banking Chatbots and Its Impact on Brand Love: The Moderating Role of Perceived Risk," Journal of Internet Commerce, vol. 18, no. 1, pp. 91-111, 2019.

[15] G. S. Dawson, E. Karahanna, and A. Buchholtz, "A study of psychological contract breach spillover in multiple-agency relationships in consulting professional service firms," Organization Science, vol. 25, no. 1, pp. 149-170, 2013.

[16] D. E. Leidner, E. Gonzalez, and H. Koch, "An affordance perspective of enterprise social media and organizational socialization," The Journal of Strategic Information Systems, vol. 27, no. 2, pp. 117-138, 2018.

[17] R. Meyer von Wolff, S. Hobert, and M. Schumann, "How May I Help You?-State of the Art and Open Research Questions for Chatbots at the Digital Workplace," in Proceedings of the 52nd Hawaii International Conference on System Sciences, 2019.

[18] J. Weizenbaum, "ELIZA---a computer program for the study of natural language communication between man and machine," Communications of the ACM, vol. 9, no. 1, pp. 36-45, 1966.

[19] A. Venkatesh et al., "On evaluating and comparing conversational agents," arXiv preprint arXiv:1801.03625, vol. 4, pp. 60-68, 2018.

[20] S. Bernanzzani, "How Chatbots Can Improve User Experience " in HubSpot vol. 2019, ed, 2018.

[21] Z. Xue, T.-Y. Ko, N. Yuchen, M.-K. D. Wu, and C.-C. Hsieh, "Isa: Intuit Smart Agent, A Neural-Based Agent-Assist Chatbot," in 2018 IEEE International Conference on Data Mining Workshops (ICDMW), 2018, pp. 1423-1428: IEEE. 
[22] C. Smith, "An employee's best friend? How AI can boost employee engagement and performance," Strategic HR Review, vol. 18, no. 1, pp. 17-20, 2019.

[23] J. J. Li, M. A. Bonn, and B. H. Ye, "Hotel employee's artificial intelligence and robotics awareness and its impact on turnover intention: The moderating roles of perceived organizational support and competitive psychological climate," Tourism Management, vol. 73, pp. 172-181, 2019.

[24] J. Gibson, The Ecological Approach to Visual Perception. Hillsdale, New Jersey: Lawrence Erlbaum Associates, 1986.

[25] T. A. Stoffregen, "Affordances as properties of the animal-environment system," Ecological psychology, vol. 15, no. 2, pp. 115-134, 2003.

[26] I. Hutchby, "Technologies, texts and affordances," Sociology, vol. 35, no. 2, pp. 441-456, 2001.

[27] O. Volkoff and D. M. Strong, "Critical realism and affordances: Theorizing IT-associated organizational change processes," Mis Quarterly, pp. 819-834, 2013.

[28] A. Majchrzak and L. M. Markus, "Technology Affordances and Constraints in Management Information Systems (MIS)," in Encyclopedia of Management Theory, E. Kessler, Ed., ed. Forthcoming: Sage Publications, 2012.

[29] S. Faraj and B. Azad, "The materiality of technology: An affordance perspective," Materiality and organizing: Social interaction in a technological world, vol. 237, pp. 1-28, 2012.

[30] G. Pozzi, F. Pigni, and C. Vitari, "Affordance theory in the IS discipline: A review and synthesis of the literature," in AMCIS 2014 Proceedings, 2013.

[31] D. M. Strong et al., "A theory of organization-EHR affordance actualization," Journal of the Association for Information Systems, vol. 15, no. 2, pp. 53-85, 2014.

[32] E. Stoeckli, F. Uebernickel, and W. Brenner, "Exploring Affordances of Slack Integrations and Their Actualization Within Enterprises-Towards an Understanding of How Chatbots Create Value," in Proceedings of the 51st Hawaii International Conference on System Sciences, 2018.

[33] O. Henfridsson and B. Bygstad, "The generative mechanisms of digital infrastructure evolution," MIS quarterly, pp. 907-931, 2013.

[34] P. Hedström, R. Swedberg, and G. Hernes, Social mechanisms: An analytical approach to social theory. Cambridge University Press, 1998.

[35] J. Mingers, A. Mutch, and L. Willcocks, "Critical realism in information systems research," MIS quarterly, vol. 37, no. 3, pp. 795-802, 2013.

[36] B. Bygstad and B. E. Munkvold, "In search of mechanisms. Conducting a critical realist data analysis," in Thirty Second International Conference on Information Systems, Shanghai, China, 2011: AISeL.

[37] T. Wengraf, Qualitative research interviewing: Biographic narrative and semi-structured methods. London: Sage, 2001.

[38] M. D. Myers and M. Newman, "The qualitative interview in IS research: Examining the craft,"
Information and organization, vol. 17, no. 1, pp. 2-26, 2007.

[39] B. Bygstad, B. E. Munkvold, and O. Volkoff, "Identifying generative mechanisms through affordances: a framework for critical realist data analysis," Journal of Information Technology, vol. 31, no. 1, pp. 83-96, 2016.

[40] D. Wynn Jr and C. K. Williams, "Principles for conducting critical realist case study research in information systems," MIS quarterly, pp. 787-810, 2012.

[41] S. Paavola, "Abduction as a logic and methodology of discovery: The importance of strategies," Foundations of Science, vol. 9, no. 3, pp. 267-283, 2004.

[42] V. Braun and V. Clarke, "Using thematic analysis in psychology," Qualitative Research in Psychology, vol. 3, no. 2, pp. 77-101, 2006/01/01 2006.

[43] L. Waizenegger, "Connectivity as a Two-Edged Sword: Mirroring the Multifaceted Field of Constant Connectivity," in 12th International Conference on Wirtschaftsinformatik, Osnabrück, 2015, pp. 1527 1541: AIS.

[44] C. Chen, K. Z. Zhang, X. Gong, S. J. Zhao, M. K. Lee, and L. Liang, "Understanding compulsive smartphone use: An empirical test of a flow-based model," International Journal of Information Management, vol. 37, no. 5, pp. 438-454, 2017.

[45] H. Ritchie and M. Roser, "Mental Health," in Our world in data vol. 2019, ed, 2018.

[46] R. D. Tristiana, A. Yusuf, R. Fitryasari, S. D. Wahyuni, and H. E. Nihayati, "Perceived barriers on mental health services by the family of patients with mental illness," International journal of nursing sciences, vol. 5, no. 1, pp. 63-67, 2018.

[47] DataReportal, "DIGITAL 2019: GLOBAL DIGITAL OVERVIEW," Datareportal2019, Available: https://datareportal.com/reports/digital-2019-globaldigital-overview.

[48] R. Nowland, E. A. Necka, and J. T. Cacioppo, "Loneliness and social internet use: pathways to reconnection in a digital world?," Perspectives on Psychological Science, vol. 13, no. 1, pp. 70-87, 2018.

[49] J.-H. Kim, "Psychological issues and problematic use of smartphone: ADHD's moderating role in the associations among loneliness, need for social assurance, need for immediate connection, and problematic use of smartphone," Computers in Human Behavior, vol. 80, pp. 390-398, 2018.

[50] T. B. White, "Consumer disclosure and disclosure avoidance: A motivational framework," Journal of Consumer Psychology, vol. 14, no. 1-2, pp. 41-51, 2004.

[51] M. Mazmanian, "Avoiding the Trap of Constant Connectivity: When Congruent Frames Allow for Heterogeneous Practices," (in English), Academy of Management Journal, vol. 56, no. 5, pp. 1225-1250, Oct 2013.

[52] M. A. K. Siddike and Y. Kohda, "Co-creating Value in People's Interactions with Cognitive Assistants: A Service-System View," Journal of Creating Value, vol. 4, no. 2, pp. 255-272, 2018. 